\title{
ONGs brasileiras em Boston ${ }^{1}$
}

\author{
TERESA SALES
}

\section{Introdução}

$\mathrm{D}$ EZ DE ABRIL de 2006. O palco está armado para encerrar mais uma mobilização dos imigrantes em Boston, na forma de uma passeata nas ruas centrais daquela cidade, para exigir a aprovação de leis mais justas e que permitam a legalização dos imigrantes indocumentados. Dessa vez, a mobilização contou com a presença marcante dos imigrantes brasileiros. Os organizadores calculam que estiveram presentes na passeata cerca de mil brasileiros. Só de Framingham vieram três ônibus, sendo um deles lotado de estudantes. A presença brasileira não ficou visível apenas nas cores verde-amarelo das bandeiras e camisetas de muitos daquele participantes. No palco, a coordenação do ato ficou por conta de Marcony Almeida, tendo Paulo Pinto como mestre de cerimônia e Heloísa Galvão como uma das oradoras para um público total de cerca de sete mil participantes (informações obtidas por internet com Heloísa Galvão).

Essa mobilização marcou um grande avanço na organização política dos imigrantes brasileiros, o que confirma as conclusões deste artigo. Segundo depoimento de Fausto Mendes da Rocha, diretor do Centro do Imigrante Brasileiro em Boston, reportada por Paulo Sotero (O Estado de S. Paulo, 23.4.2006), um fato importante ocorrido nesse abril de lutas foi a participação das igrejas. Os pastores evangélicos e os padres católicos abriram seus templos para que os líderes pudessem falar sobre a reforma das leis de imigração e convocassem os fiéis para as mobilizações; e, por sua vez, dez pastores e seis padres brasileiros estiveram presentes à marcha do dia 10.

Primeiro de maio de 2006. Para esse dia está prevista mais uma manifestação dos imigrantes nos Estados Unidos na forma de um dia de protesto, o Dia Sem Imigrantes. ${ }^{2}$

O motivo maior dessas várias formas de mobilização dos imigrantes em mais de cem cidades norte-americanas é tentar influir no debate em curso no Senado e na Câmara dos Deputados sobre os projetos de lei atualmente em discussão naquelas duas casas do Poder Legislativo. $\mathrm{O}$ foco das reivindicações é a abertura de um caminho para a legalização e a cidadania dos imigrantes, assim como a velha bandeira da reunificação familiar.

O projeto da Câmara, que já foi aprovado em dezembro de 2005 em plenário, não é aceito pelos imigrantes, pois criminaliza os doze milhões de imigrantes indocumentados impondo sua detenção e deportação, e cria uma pena de cinco anos para quem ajudar imigrantes ilegais a entrar ou permanecer no país. Já o projeto do Senado, de autoria do senador democrata de Massachusetts Ted Kennedy e do senador republicado do Arizona John Mc-Cain, que até agora foi 


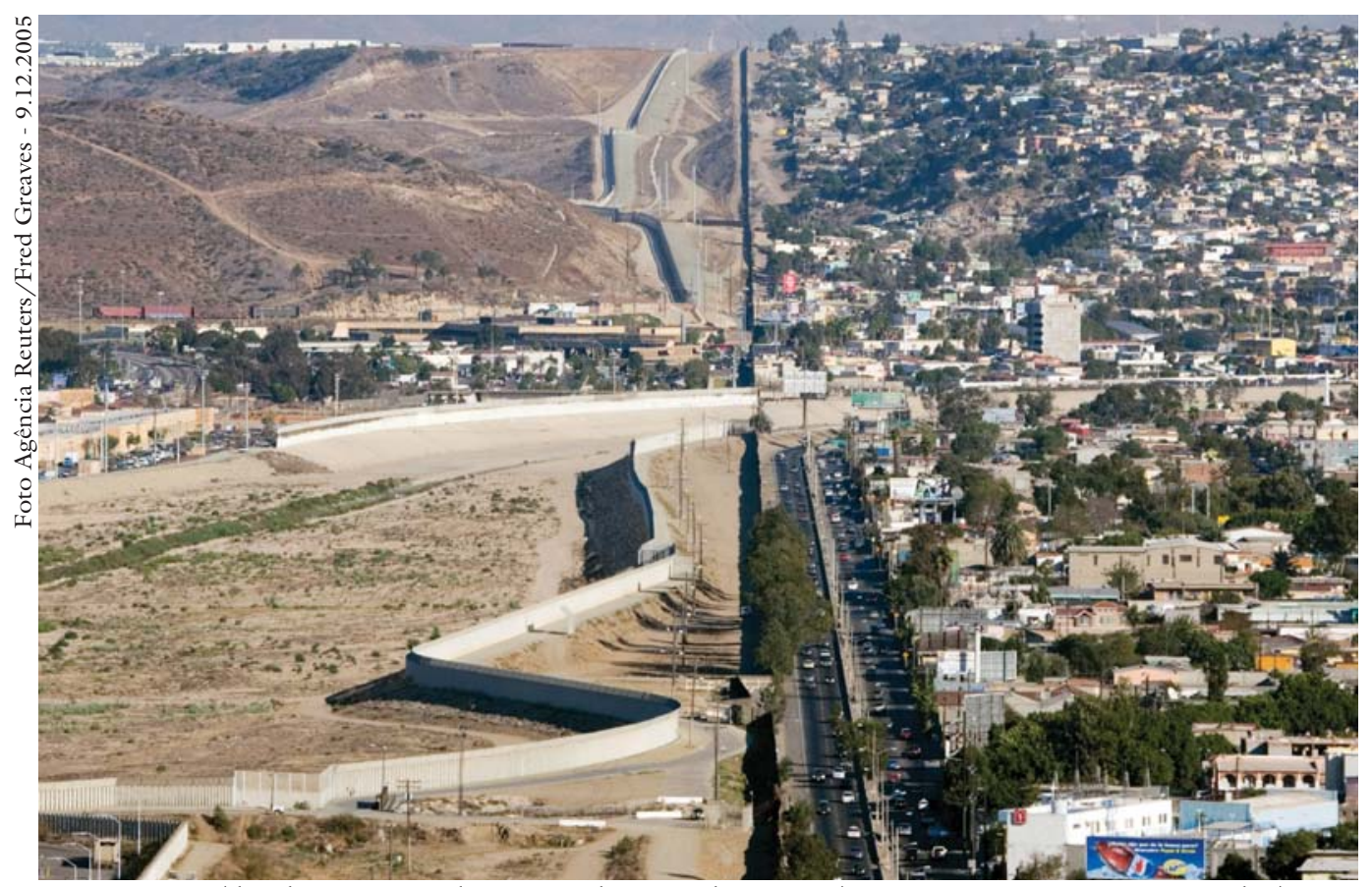

As cercas múltiplas separando os Estados Unidos e o México, em San Diego, na Califórnia.

aprovado somente em comissão, tem pontos que interessam mais aos imigrantes, pois prevê uma rápida legalização dos oito milhões de imigrantes indocumentados há mais de cinco anos (O Estado de S. Paulo, 23.4.2006).

Ambos os projetos de lei abordam a questão da fronteira entre o México e os Estados Unidos. O da Câmara dos Deputados destina uma verba de US\$ 2,2 bilhões para a construção de mais cercas naquela fronteira, e o do Senado prevê a instalação de sensores no solo e o uso de aviões teleguiados, além de uma verba para duplicar o atual contingente da Patrulha de Fronteira. A perseguição aos imigrantes que tentam atravessar aquela fronteira tem sido destacada pelos meios de comunicação e é assunto tão corriqueiro nos Estados Unidos que, recentemente, foi lançado um jogo virtual - Border Patrol - no qual ganha pontos quem atingir mais imigrantes ilegais atravessando a fronteira ( $O$ Estado de S. Paulo, 28.4.2006).

Dentre os imigrantes que tentam atravessar a fronteira México-Estados Unidos, destacam-se os brasileiros. ${ }^{3}$ Assim, cerca de dois meses após o início da novela América da Rede Globo de Televisão, o jornal Folha de S.Paulo (5.5.2005) apresentou, na matéria "Captura de brasileiros nos EUA decuplica", dados impressionantes:

apenas em abril, 4.802 brasileiros foram detidos em território americano da fronteira com o México - uma incrível média de 160 casos diários, segundo dados fornecidos pela Patrulha da Fronteira a pedido da Folha. O número é mais de dez vezes o registrado no mesmo período do ano passado: 443 casos (15 por dia).

Essa notícia reacendeu o debate em torno da questão migratória de bra- 


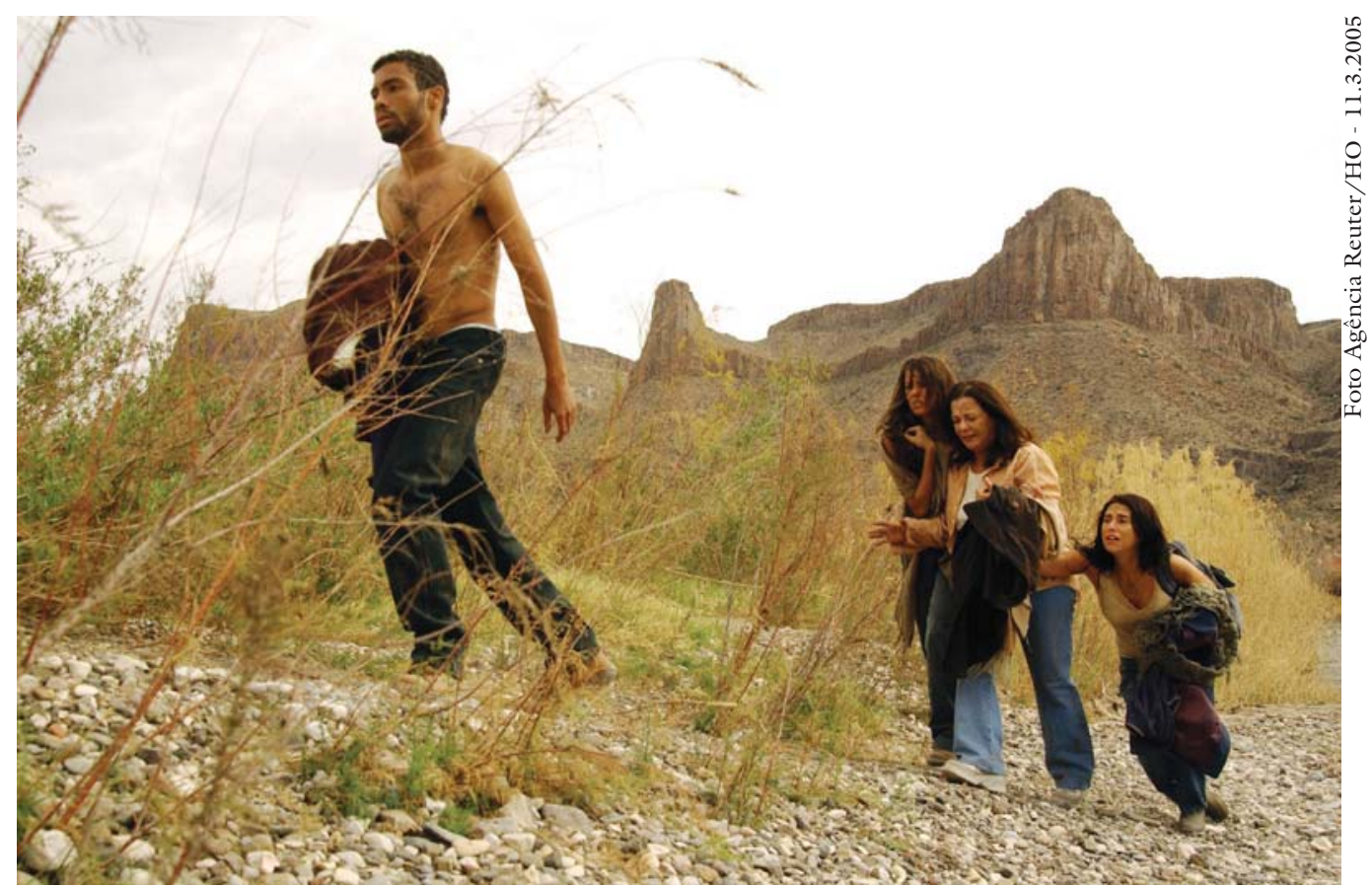

Atores da novela América, da TV Globo, gravam cena na fronteira dos EUA e do México.

sileiros para os Estados Unidos em vários meios de comunicação e até no Congresso Nacional, e um representante do Ministério das Relações Exteriores, um outro do Ministério da Justiça, Glória Perez - autora da novela América - e eu fomos convidados a participar de uma Audiência Pública da Comissão de Relações Exteriores e Defesa Nacional do Senado Federal sobre o tema.

$\mathrm{Eu}$, que já tinha dado por encerrada minha pesquisa com imigrantes brasileiros nos Estados Unidos depois de escrever um circunstanciado artigo sobre a "Segunda geração" (Sales \& Loureiro, 2004), voltei ao tema. Para participar da audiência pública, fiz contato por e-mail com uma rede de lideranças das organizações de brasileiros nos Estados Unidos e retomei contatos, o que me despertou para um novo projeto, de natureza mais jornalística, posto que circunscrito a um curto espaço de tempo. Participei de um "Encontro de Lideranças Brasileiras nos Estados Unidos” em Boston, de 21 a 23 de outubro de 2005, e realizei treze entrevistas com líderes da comunidade brasileira, visando avaliar a organização dos brasileiros imigrantes dez anos depois da pesquisa de 1995-1996, que deu origem ao livro Brasileiros longe de casa (Sales, 1999).

Ao visitar mais uma vez os brasileiros imigrantes na região de Boston, foi possível observar que a visão da imprensa brasileira é muito parcial, no sentido negativo, em relação aos nossos imigrantes lá fora. Isso talvez seja decorrência de como a sociedade brasileira encara esses imigrantes: eles ferem a nossa autoimagem de país acolhedor. Não gostamos de ver nossos cidadãos saindo de casa e, sobretudo, de ver que muitos deles estão entrando na casa alheia pela porta dos fundos. Contudo, numa perspectiva histórica, é importante lembrar que foi assim também com outros povos que hoje são respeitáveis cidadãos norte- 
americanos, brasileiros, argentinos, só para citar o continente americano. Ao enfatizar apenas os aspectos negativos da migração de brasileiros para outros países, a imprensa reforça um estereótipo já existente na sociedade em relação a esses migrantes.

Sem pretender entrar no mérito dessa questão, este artigo tem o objetivo fazer uma análise comparativa, entre 1995 e 2005, dos grupos organizados de imigrantes brasileiros, com ênfase no Estado de Massachusetts. Com isso, procuro mostrar que, para além das prisões e deportações, os brasileiros longe de casa têm construído uma marca de povo trabalhador, solidificando seus vínculos organizativos e caminhando a passos largos para um reconhecimento no seio da sociedade norte-americana, mesmo que isso possa lhe causar uma contraofensiva por parte daquela sociedade em algumas localidades, como é o caso da cidade de Framingham.

\section{Americanos contra brasileiros}

Framingham é conhecida por ser a maior Town de Massachusetts - incorporada nesse sistema desde 1700 -, pois todas as demais cidades do seu tamanho são constituídas administrativamente como cities. As várias tentativas de mudança de regime de governo local de Town para City nunca prosperaram. Ali se elege não um prefeito, mas sim uma espécie de Conselho de Cidadãos, o Town Meeting, que, por sua vez, elege cinco selectmen, entre os quais um é escolhido como town manager. O Board of Selectmen e o Town Manager formam o Poder Executivo da cidade e o Town Meeting corresponde ao Poder Legislativo. A cidade é dividida em dezoito Precincts (distritos eleitorais) e existem doze membros do Town Meeting que representam cada distrito, totalizando, portanto, 216 representantes do Poder Legislativo na cidade, com mandato de três anos, e a cada ano quatro são eleitos. Essa forma de governo da cidade difere daquela de uma Open Town Meeting, mais semelhante às antigas cidades-Estado, em que cada residente pode votar no Town Meeting. ${ }^{4}$

Atualmente, dois brasileiros fazem parte do Town Meeting. Na mesma ocasião em que esses brasileiros foram eleitos, um cidadão norte-americano, Joe Rizolli, hoje muito conhecido de toda a comunidade brasileira, também se candidatou, mas não obteve o número de votos necessários para ser eleito. Quem é esse senhor?

Em finais de 2003, Joe Rizolli, co-fundador do "Concerned Citizens and Friends of Immigration Law Enforcement", um grupo que se opõe publicamente à imigração ilegal, declarou em uma reunião do Board of Selectmen de Framingham que a cidade tem sido raped pelos imigrantes brasileiros. Rape significa, em português, raptar, estuprar, saquear. Nos Estados Unidos, o verbo é mais comumente usado para designar o seu sentido mais duro: estuprar. Outras pessoas do mesmo grupo afirmaram que os imigrantes brasileiros estavam drenando a economia local, ao enviarem mensalmente milhares de dólares de seus salários para o Brasil e ao se beneficiarem dos programas sociais locais. 
Em outra ocasião, Joe Rizolli e Jeffrey Buck, ambos co-diretores da referida associação, disseram que estavam apenas preocupados com o fato de os imigrantes ilegais estarem desrespeitando as leis, referindo-se mais aos brasileiros do que a outros grupos imigrantes, porque eles eram o maior grupo de estrangeiros ilegais em Framingham, segundo estimativas da própria comunidade brasileira. ${ }^{5}$

Essa situação inusitada de xenofobia contraria totalmente a matéria do Boston Globe de dezembro de 1994, citada anteriormente, na qual os imigrantes brasileiros eram vistos como forjando uma nova identidade em Framingham para o próximo século. Naquela época não se imaginava que, uma década mais tarde, os Estados Unidos estariam sob um governo republicano que abriria espaço para esse e outros tipos de manifestações de intolerância para com os imigrantes. Desde o desencadeamento desse movimento antiimigrante brasileiro em Framingham, os brasileiros ali residentes têm lidado em seu dia-a-dia com esse fantasma de forças contrárias que estão à espreita em plena luz do dia.

A presidente atual da Bramas não tem dúvida de que esse movimento representa não apenas o pensamento dos dirigentes daquela associação, mas também de uma ampla camada dos habitantes da cidade, sobretudo daqueles residentes no lado norte. Essa região é predominantemente residencial e seus moradores desfrutam de melhor qualidade de vida. A população é constituída, sobretudo, pelos descendentes dos mais antigos moradores locais, com idade média mais avançada do que os demais habitantes (Sales, 1999). Já no lado sul da cidade, estabeleceram-se originalmente as indústrias, seguindo as obras de infra-estrutura ao longo dos trilhos da ferrovia. A classe operária passou a morar nessa área no início do surto industrial de Framingham, em finais do século XIX até meados do XX. Depois foram os porto-riquenhos e asiáticos que foram morar ali. Essa parte da cidade caracteriza-se pelo predomínio de uma população mais pobre, mais jovem e não-americana; é nesse local que mora a maioria dos imigrantes brasileiros.

O clima republicano repressivo que predomina nos Estados Unidos, desde a primeira eleição de George W. Bush e, sobretudo, depois dos atentados de 11 de setembro de 2001, é um fator que favorece tais manifestações de xenofobia. A declaração de Bush, de que o objetivo de seu governo é deportar, sem exceção, todas as pessoas que entram ilegalmente no país, foi destacada pela imprensa norte-americana.

O movimento antiimigração de Framingham não só faz parte desse clima republicano repressivo, como também é conseqüência da maior visibilidade e organização dos brasileiros imigrantes, o que não acontece em outras cidades da Grande Boston, onde os brasileiros têm também forte presença, mas não aparecem tanto quanto em Framingham. Esse destaque dos imigrantes brasileiros resulta, por sua vez, de dois fatores principais: a organização dos brasileiros imigrantes e a revitalização do centro da cidade e conseqüente revalorização de seus imóveis. É como se os antigos habitantes estivessem a dizer: "Vão embora, vocês já cumpriram sua parte, agora queremos o centro da cidade de volta para nós". 


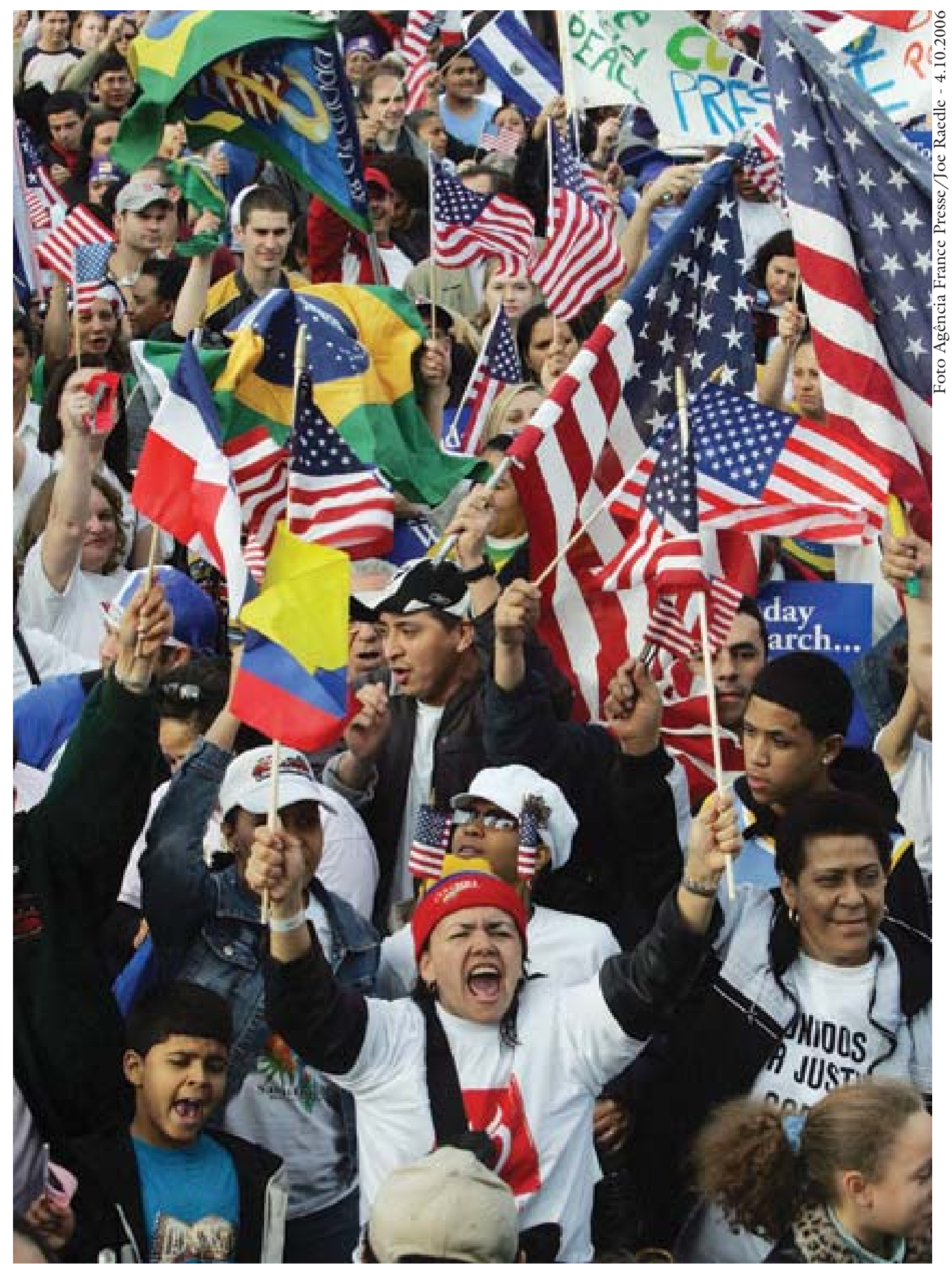

Os protestos nos EUA contra as leis de imigração têm a participação de brasileiros em Boston.

Esses dois fatores estão inter-relacionados, pois a organização dos brasileiros passa também pela sua forte presença como negociantes bem-sucedidos no centro da cidade. Antes mesmo da fundação da Bramas e da Associação de Cidades Irmãs Framingham-Governador Valadares, vários brasileiros, já há cerca de uma década, começaram a participar ativamente em outras organizações norte-americanas da 
localidade, como nas escolas públicas, na South Middlesex Oportunity Council (SMOC), na South Middlesex Area Chamber of Commerce (SMACC), ${ }^{6}$ e em associações como Rotary, Lyons e Maçonaria. Mais recentemente, como já mencionado, dois brasileiros foram eleitos para o Poder Legislativo da cidade. Numa localidade com mais habitantes, como é o caso do município de Boston, essa presença brasileira ativa não teria tanto destaque quanto em Framingham.

Há atualmente um enorme ruído entre os líderes de comunidade de Framingham: desencontros de informações e intrigas, que poderiam indicar um retrocesso na organização da comunidade. Há relatos sobre pessoas que se desencantaram e abandonaram o trabalho comunitário e de um líder comunitário que simplesmente se desorganizou psiquicamente. Entretanto, se alguns saem do movimento, são muito mais os que entram os que se mobilizam; afinal, a discórdia nem sempre determina o fracasso, servindo, muitas vezes, para apurar os processos organizativos e definir melhor as lideranças. Foi assim, por exemplo, em relação a uma outra organização de brasileiros de Boston (hoje possivelmente a de maior destaque entre os imigrantes brasileiros da Boston metropolitana): o Centro do Imigrante Brasileiro.

Quanto ao segundo fator de visibilidade dos imigrantes brasileiros - a revitalização do centro da cidade e a conseqüente revalorização dos imóveis ocupados pelos imigrantes -, foram identificadas, na pesquisa de 1995, 31 casas de comércio ou de serviços de brasileiros, a maioria no centro de Framingham: cinco restaurantes; cinco cabeleireiros; quatro lojas de vendas de passagens e transporte; quatro lojas de seguros; quatro de produtos brasileiros e remessas; três oficinas mecânicas; duas joalherias; uma boutique; uma padaria; uma loja de eletrodomésticos; e um escritório de contador. Essa quantificação foi possível, na época, por meio de uma listagem cedida pelo responsável pela distribuição de jornais brazucas, que se destinam a todos os locais por onde circulam brasileiros. Para a pesquisa atual, recorreu-se a uma publicação também distribuída gratuitamente nas lojas e a outros locais freqüentados por brasileiros. Trata-se de uma lista amarela, a "Brazilian Superlist", que abrange os Estados de Califórnia, Connecticut, Flórida, Geórgia, Massachusetts, New Jersey, Nova York, Pensilvânia e outros estados. ${ }^{7}$

Na "Brazilian Superlist" de 2005 foram identificadas 71 casas de comércio ou de serviços de brasileiros, a maioria também no centro de Framingham; ou seja, nesses últimos dez anos, o número de comércios e serviços de brasileiros mais do que duplicou. Desses estabelecimentos, $40 \%$ estão localizados na principal rua do centro de Framingham - a Concord St., onde fica a prefeitura -, e $22 \%$ em outras ruas igualmente centrais - a Union St. e a Hollis St. Além desse aumento, observou-se também uma maior diversificação nos ramos de atividade. $^{8}$

O edifício Arcade, situado num espaço nobre da Concord St., é sede de várias dessas atividades de comércio ou de serviços. Com $90 \%$ de suas salas alugadas por brasileiros, incluindo consultórios, lojas, sedes de duas das organiza- 
ções de brasileiros (a Bramas e o Centro Bom Samaritano, que aliás não constam na "Brazilian Superlist"), é um exemplo do processo de valorização dos imóveis no centro de Framingham. Segundo a atual presidente do Bramas, o uso desse edifício irá mudar, sendo ampliado e parcialmente destinado a residências. Os aluguéis atualmente pagos pelos negociantes e profissionais brasileiros, em torno de US\$ 300 por mês, passariam para US\$ 1.400 a US\$ 1.800. A maioria dos atuais brasileiros do Arcade certamente não terá recursos para arcar com esse valor, e o contrato de locação prevê apenas um aviso de trinta a sessenta dias para desocupação das salas. A presidente da Bramas é pessimista quanto à situação não apenas dos brasileiros do Árcade, mas também de outros negociantes do centro da cidade, pois, segundo ela, esse é o início de um movimento de retomada pelos nativos de seu centro da cidade. Há, contudo, opiniões contrárias às dela, que afirmam que o proprietário do prédio tem conversado com os atuais inquilinos, assegurando-lhes prioridade no aluguel das novas salas.

O tempo dirá quem tem razão. Ainda estão faltando estudos que, à semelhança daqueles que mostram a revitalização de centros decadentes e despovoados pelas chamadas "empresas étnicas" dos imigrantes (Halter, 1995), apresentem agora sua outra face: o processo de retomada, pelos nativos descontentes, dos centros reconstituídos pelos imigrantes, com a justificativa de presença de estrangeiros ilegais em seu território, ou, em outros casos, de uma afirmação étnica de gerações já estabelecidas. A situação não apenas nos Estados Unidos, mas também nos países receptores de imigrantes, entre os quais o caso da França é o exemplo paradigmático, aponta um quadro sombrio para o futuro imediato.

\section{Organizações - Balanço de dez anos}

Como a maior parte dos imigrantes que chegam a um país estrangeiro, os brasileiros também procuraram inicialmente, na região de Boston, o conforto das igrejas. Uma das igrejas católicas procurada pelos brasileiros foi a de Santo Antônio, em Cambridge, construída pelos portugueses e com as missas celebradas em português por um dos primeiros padres que chegaram a Boston para atender à comunidade brasileira. Os pastores protestantes de várias denominações, por sua vez, foram chegando, celebrando os cultos em lugares improvisados e, posteriormente, juntando dinheiro da própria comunidade para a construção de suas igrejas. Esse foi o marco inicial da organização dos brasileiros. Além do conforto espiritual, os imigrantes também encontram nas igrejas um espaço de sociabilidade e de ajuda, com indicações para suas demandas mais imediatas de moradia, trabalho, escolas para os filhos e serviços de saúde.

Com o padre brasileiro em Cambridge, as missas passaram a ter um ritual mais moderno e alegre, com as músicas acompanhadas por guitarra e os brasileiros se confraternizando ao final, no salão paroquial, com café e pão de queijo. Entretanto, numa comemoração do 7 de Setembro, o padre resolveu fazer uma missa ainda mais festiva e providenciou uma bandeira do Brasil para ser colocada ao lado das outras já existentes de Portugal e dos Estados Unidos. 
Por infelicidade, a bandeira brasileira era maior do que a portuguesa, e isso foi a gota d'água para um certo descontentamento dos portugueses, que constituíam uma comunidade mais velha que não andava satisfeita com as modernidades do padre brasileiro, interpretando o incidente da bandeira como um sinal de que os brasileiros estavam querendo tomar conta daquela igreja que eles haviam construído com muito esforço.

Esse foi, porém, apenas o começo. Logo, outros padres foram chegando e descobrindo as igrejas construídas pelos italianos, irlandeses, latinos da América Central e do Sul, e foram abrindo mais espaços para suas missas e atividades comunitárias em português. Do lado dos protestantes, um pastor da Igreja Assembléia de Deus tinha construído, em 1993, um enorme templo para duas mil pessoas, em Somerville; em 1994, outro pastor havia comprado um prédio de três andares de um antigo convento católico dos padres beneditinos, no bairro de Charlestown, em Boston, para instalar a Primeira Igreja Batista Brasileira da Grande Boston.

Nas dependências dessa igreja Batista, foi criado, em 1995, o "Brazilian Community Center", que, com os parcos recursos de um grant inicial de US\$ $5.000,00$, destinava-se a aulas de inglês e de computação, bem como à distribuição de roupas e alimentos em razão de Natal que se aproximava. Entretanto, os objetivos do centro eram bastante abrangentes e sua inauguração foi pomposa, contando com a presença do cônsul brasileiro e de várias lideranças comunitárias. Esse centro teve, porém, vida curta, como aconteceu também com uma outra organização que, durante a minha pesquisa em 1995, era muito atuante na região de Boston: a "Brazilian Professional Network".

Diferentemente das demais, que foram todas iniciativas de brasileiros, essa organização foi fundada por um advogado norte-americano (casado com uma brasileira), tendo, porém, como público-alvo os brasileiros, sobretudo os emergentes negociantes dos centros de Framingham, de Somerville e dos bairros de Allston e East Boston, em Boston. A principal atividade dessa organização era promover reuniões mensais para tratar de assuntos de interesse da comunidade. Contando sempre com um ou mais expositores convidados, eram abordados temas diversos, tais como promoção de contatos com organizações hispânicas, divulgação dos resultados do Censo Americano de 1990, exposição de uma linha de créditos do BankBoston para imigrantes (quando o então presidente do banco era o brasileiro Henrique Meireles) e promoção de um contato com o deputado federal Joe Kennedy. Esse advogado, que hoje colhe os dividendos desse investimento, é um atuante profissional vinculado aos brasileiros e possui escritórios em Framingham e Boston. Na "Brazilian Superlist", ele dispõe de uma página inteira, na qual, abaixo de seu nome, está escrito "o advogado dos brasileiros", citando sua especialidade: acidentes de automóvel, acidentes de pedestres, mordidas de cachorro (sic) e acidentes em geral.

A Bramas, de certa maneira, veio substituir a "Brazilian Professional Network", pois originou-se entre os negociantes brasileiros de Framingham que tinham presença marcante nas reuniões mensais dessa última organização. 
As duas organizações que vi nascer em 1995 e que comemoraram seus dez anos em 2005 foram o "Grupo Mulher Brasileira” e o "Centro do Imigrante Brasileiro", ambos situados no bairro de Allston, em Boston, e com as mesmas pessoas à frente desde então. $\mathrm{O}$ "Grupo Mulher Brasileira", segundo sua diretora executiva, conseguiu se manter nesse período, mas não deu o "pulo do gato", tal como o "Centro do Imigrante Brasileiro", porque não teve ainda condições de ter um pessoal fixo remunerado para desenvolver as atividades, e todo o trabalho é voluntário, com exceção da recente contratação de uma pessoa para trabalhar dez horas por semana, que deverá permanecer por dez meses. Apesar de a presidente do grupo ser a única que o freqüenta com regularidade, não houve, segundo ela, um afastamento total das participantes, que sempre aparecem em ocasiões especiais, tais como nas palestras e eventos, colaborando quando podem. É um grupo que está sempre presente nos eventos e esteve à frente da organização de todos os Festivais da Independência do Brasil, em Boston, desde que esse começou, há dez anos.

$\mathrm{O}$ contato com as universidades e com estudantes e alguns professores brasileiros vem trazendo benefícios para essas organizações; dentre estas, algumas se beneficiaram desse contato de uma forma mais efetiva, por meio de projetos em parceria com a Universidade de Massachusetts de Lowel. No "Centro do Imigrante Brasileiro" há um projeto com jovens na área de saúde e segurança no trabalho; e no "Grupo Mulher Brasileira" é desenvolvido um projeto de formação de uma cooperativa de faxineiras. Essas parcerias propiciam, além da verba para realização dos projetos, também um intercâmbio frutífero da academia com as organizações comunitárias.

O “Centro do Imigrante Brasileiro" foi concebido, em 1995, por um jovem idealista a partir de sua própria experiência migratória. Tendo chegado a Boston em 1988, seu primeiro emprego foi em uma companhia de limpeza, na qual teve problemas trabalhistas e recorreu a uma organização criada para atender os imigrantes latinos, a "Immigration Work Result Center" (IWRC). Resolveu seu problema na empresa e, a partir daí, passou a fazer trabalho voluntário nessa organização. Dessa experiência nasceu a idéia de fundar uma organização para os próprios brasileiros. Com a orientação de uma iraniana (casada com um brasileiro) que fazia parte da IWRC, ele criou o "Centro do Imigrante Brasileiro" em março de 1995.

Logo depois, em abril do mesmo ano, um outro jovem que tivera problemas trabalhistas na empresa de lasdscape, onde trabalhava, recorreu ao "Centro", resolveu seu problema e passou a fazer ali trabalho voluntário. Quando os entrevistei, em finais de 1995, ambos eram igualmente comprometidos com o trabalho e estavam fazendo um curso oferecido pela Universidade de Massachusetts, destinado ao treinamento de líderes comunitários sobre desenvolvimento e leis norte-americanas de imigração. Nessa época, o "Centro" nem sequer possuía uma sede e dispunha apenas de uma mesa e um telefone numa sala onde funcionava uma representação da "Massachusetts Agence for Portuguese Speakers" (Maps) e um curso de inglês para brasileiros, no centro de Allston, um dos bairros de concentração de brasileiros em Boston. 
Nessa época, eles contavam com algum dinheiro que haviam arrecadado em uma festa e com uma equipe de advogados norte-americanos que trabalhavam voluntariamente para comunidades imigrantes e podiam ser acionados para os casos difíceis, pois, nos mais simples, os acordos podiam ser conseguidos por meio de telefonema deles próprios, geralmente em inglês, para um entendimento com o empregador. Ainda sem registro próprio, o "Centro" conseguiu, em outubro de 1995, o seu primeiro Grant, pela intermediação da mesma iraniana que havia dado a mão generosa em sua fundação.

Aos dez anos de existência do "Centro do Imigrante Brasileiro", apenas o seu fundador, entre os cinco membros que participavam no início, permanece como diretor executivo. Nesses anos, foram muitas as dissensões, mas também muitos os apoios vindos de todo lado. Hoje o "Centro" tem uma organização consolidada por um Board of Directors de nove membros, um staff de seis membros (três trabalhando em tempo integral e três em tempo parcial) e tem recebido suporte financeiro de cerca de doze fundações norte-americanas. Sua missão é a defesa da comunidade brasileira em Massachusetts em questões de educação, direitos trabalhistas - seu principal foco de atuação - e outros direitos do imigrante.

Nesta última pesquisa, entrevistei o diretor executivo de outro "Centro" com uma missão semelhante à do "Centro do Imigrante Brasileiro", de Allston, mas que é mais recente e atende sobretudo à comunidade brasileira da região de East Boston. Trata-se do "Centro do Trabalhador Brasileiro", sediado em uma das salas do prédio do Serviço Social de East Boston desde 2004, e antes disso, em uma igreja católica da região. ${ }^{9}$ A gênese desse "Centro" vem da atuação de uma brasileira imigrante que hoje está de volta ao Brasil, mas que, em 1995, quando fiz a pesquisa, era uma pessoa muito atuante na área de East Boston. $\mathrm{Na}$ época, ela era vinculada a um Conselho Ecumênico da Comunidade de East Boston e foi lá que começou sua atuação voltada para os brasileiros. O "Centro do Trabalhador Brasileiro" foi criado em 2000 por essa imigrante e um norteamericano de Cambridge, com a ajuda da Igreja Católica, tendo então o nome de "Ana da Hora Work Center". Em 2002, mudou para a denominação atual.

Assim como o de Allston, esse "Centro" também é mantido principalmente por fundações norte-americanas, e secundariamente pelos recursos das aulas de inglês; funciona com um staff fixo (nesse caso, somente o diretor executivo em tempo integral e uma secretária em tempo parcial) e um Conselho de Diretores que se reúne regularmente. Aliás, as atividades dos dois "Centros" são muito semelhantes, atendendo prioritariamente a demandas trabalhistas e mantendo cursos de inglês que procuram principalmente preparar o trabalhador para as situações cotidianas no trabalho. Ambos têm alguma aproximação com os sindicatos, sobretudo o de Limpeza, que hoje possui mais de mil brasileiros associados, e o de Pintores. Outras atividades comuns não somente a esses "Centros", mas também ao "Grupo Mulher Brasileira", são as palestras sobre assuntos de interesse da comunidade (com destaque para o tema da imigração) 
e a participação em campanhas - em geral realizadas em conjuntos com outros grupos imigrantes - pela legalização, por carteira de motorista, pelo acesso à escola, e outras.

O fator que diferencia aqueles dois centros de objetivos tão semelhantes é menos a abrangência e o tamanho - o que favorece mais o "Centro do Imigrante Brasileiro", até por ser cinco anos mais antigo do que o outro - do que algumas outras características de sua atuação, que têm a ver em parte com a trajetória de seus dois dirigentes. O diretor executivo do "Centro" de Allston saiu do Brasil (Espírito Santo) com o segundo grau completo, e, nos Estados Unidos, trabalhou como imigrante ilegal em serviços não-qualificados até conseguir recursos para o "Centro" que pudessem mantê-lo por tempo integral. Sua esposa ainda trabalha como faxineira em Boston. Já o diretor executivo do "Centro" de East Boston é administrador de empresas formado em São Paulo, está em Boston há cinco anos, veio como turista para estudar inglês, tornando-se voluntário do “Centro" logo que chegou, em 2000. Depois disso, voltou ao Brasil, providenciou a documentação e retornou, em 2001, tornando-se diretor executivo em 2002. Voltou novamente ao Brasil, casou-se e trouxe a esposa, que é formada em Letras pela USP e dá aulas de português para norte-americanos. O primeiro tem uma postura de militância, de missão a cumprir, enquanto o segundo possui a frieza de um profissional. Contudo, isso explica pouco o porquê das diferenças. Esse assunto será retomado na conclusão do artigo.

Este texto não abrange todas as organizações de brasileiros imigrantes em Boston, que são em maior número do que as aqui mencionadas. Foram abordadas tão-somente aquelas com as quais tive oportunidade de manter contato e que me forneceram subsídios suficientes para as conclusões a seguir. Porém, antes de chegar às conclusões, vale fazer ainda rápidos comentários sobre algumas outras organizações. A Maps, citada anteriormente, é um caso interessante, pois tratase de uma organização antiga, sediada inicialmente em Somerville para atender os imigrantes portugueses, cuja migração é antiga em Boston, oferecendo vários serviços de assistência social. Quando começaram a chegar os imigrantes brasileiros, a Maps, além de mudar de nome para poder abranger também os brasileiros, foi estendendo cada vez mais sua atuação para esses newcomers, contratando inclusive brasileiros para essa finalidade. Hoje a entidade ainda presta serviços aos portugueses; entretanto, como seu público beneficiário e os funcionários são principalmente brasileiros - e em grande quantidade -, a agência já tem quatro sedes na região metropolitana de Boston.

Entre as organizações dos imigrantes brasileiros, existem algumas que são especialmente voltadas para atividades culturais. É o caso do "Grupo de Capoeira" fundado pelo baiano Deraldo, em Cambridge, e de um teatro financiado pela empresa de aviação TAM. Quem, nas férias de verão, for a Harvard Square (o movimentado centro daquela cidade tão universitária) verá que, entre as várias performances e shows que ali se apresentam ao ar livre para deleite dos passantes, há sempre um grupo de capoeira, que é hoje uma das marcas culturais 
do Brasil pelo mundo afora. Recentemente, quando esteve em Boston para um diálogo com a comunidade brasileira, o ministro da Cultura Gilberto Gil propôs que um Ponto de Cultura fosse montado no "Grupo de Capoeira" de Deraldo. Essa proposta foi criticada por um de meus entrevistados, que trabalha como diretor de pesquisa da prefeitura de Boston, pelo fato de o ministro não ter entrado em contato com a prefeitura para planejar melhor esse Ponto de Cultura de Boston.

Um horizonte que se vislumbra para a expansão das atividades culturais e organizativas da comunidade brasileira em Boston é uma proposta que está em estudo e que foi discutida no recente encontro de lideranças. Trata-se da disponibilização de um prédio, atualmente pertencente a uma escola da Paróquia de Santo Antônio que está sendo desativada, para atividades da comunidade brasileira. A idéia inicial é que se juntem lá organizações, como o "Grupo $\mathrm{Mu}$ lher Brasileira", o "Centro do Imigrante Brasileiro", o "Grupo de Capoeira" de Deraldo, e aos poucos o espaço seja transformado também em um "Centro Cultural Brasileiro". Isso implica arcar mensalmente com os custos do aluguel de um prédio que vale 30 milhões de dólares, chegar a um entendimento entre os possíveis ocupantes do prédio e realizar uma programação cultural que suporte parte das despesas. Será que os grupos organizados dos brasileiros imigrantes em Boston já estão preparados para esse desafio?

\section{Conclusão}

Uma leitura da descrição feita até aqui dos grupos organizados - ou, em outros termos, das organizações não-governamentais - de brasileiros imigrantes em Boston mostra, ou pelo menos indica, alguns detalhes que podem dar subsídios para responder à pergunta apresentada no final do parágrafo anterior. Até agora os brasileiros têm dado passos importantes na sua organização. Em Framingham, pela dimensão muito mais reduzida da cidade em comparação com Boston, há alguns anos eles já deixaram de ser uma população invisível, ${ }^{10}$ a ponto de começar a despertar reações antiimigrantes. Em Boston, eles se destacam, sobretudo, nos bairros de Allston e East Boston, mas isso não desencadeou as conseqüências vistas em Framingham. Alguns grupos conversam entre si, como é o caso do "Grupo Mulher Brasileira", do "Centro do Imigrante Brasileiro" e da Maps. Há, porém, uma grande distância deles em relação aos grupos de Framingham, cuja dinâmica é muito mais circunscrita à chamada região Metrowest. Porém, mesmo em Boston, os grupos de Allston têm uma relação muito tênue com os de East Boston.

Seguramente, não é apenas a localização espacial que está marcando essas fronteiras e tampouco a origem social de seus dirigentes, tal como poderia parecer à primeira vista na descrição feita na sessão anterior sobre o "Centro do Imigrante Brasileiro", em Allston, e o "Centro do Trabalhador Brasileiro", em East Boston. A entrevista com o diretor de pesquisa da prefeitura de Boston deu pistas para uma possível interpretação. Tudo indica que essas fronteiras têm a 
ver, principalmente, com uma bagagem cultural que os brasileiros levaram consigo do Brasil e reproduzem lá fora nas suas organizações. Aqui no Brasil existe uma tradição muito arraigada de os grupos da sociedade civil se organizarem politicamente, com objetivos de mudanças estruturais freqüentemente inalcançáveis em curto prazo. Já nos Estados Unidos, a tradição é de as organizações sem fins lucrativos se voltarem unicamente para a prestação de serviços, sem nenhum conteúdo político. A Maps, por exemplo, cuja expansão tem sido notável em Boston, tem essa visão muito clara e vem conseguindo apoio do governo norte-americano e das diversas fundações que lhe dão suporte financeiro.

Em relação às associações fundadas por brasileiros, se, por um lado, têm um nível de organização política invejável, tendo conseguido inclusive motivar a ida de três ministros do governo Lula para debater os problemas da comunidade, por outro, são muito frágeis no sentido da obtenção dos recursos financeiros disponíveis no governo e nas fundações norte-americanas, exatamente pela dificuldade de se organizarem em relação à prestação de serviços. Isso talvez explique a impressão que me ficou do encontro de lideranças e das entrevistas: é como se houvesse um certo hiato entre a comunidade dos imigrantes brasileiros que estão na labuta diária de um trabalho duro, construindo sua auto-imagem de povo trabalhador, e a "comunidade dos líderes". A primeira pode até se organizar, porém, quando o faz, é mais freqüentemente pelas igrejas. Essas sim têm uma ampla base de apoio nos grupos comunitários que organizam e pelos serviços que prestam, oferecidos sobretudo pelas igrejas evangélicas.

Os estudantes brasileiros às vezes se entusiasmam quando assistem às reuniões das lideranças e se propõem a ajudar a comunidade. No fundo, o que os entusiasma é compartilhar do clima de mobilização política, que em geral se acirra em momentos de campanhas por alguma reivindicação, como a legalização, a anistia, em que os líderes brasileiros, às vezes com uma base social muito menos sólida do que outros grupos imigrantes, se colocam à frente das lutas, exatamente por causa dessa bagagem que levaram consigo do Brasil.

Líderes sem base? Já ouvi por mais de uma vez um dos mais articulados membros desse grupo de líderes afirmar que ele não se considera líder porque não tem uma base, quase como uma autocrítica e uma chamada para a consciência dessa situação por parte dos demais. Essas lideranças formam uma espécie de classe média lá, distanciada da classe que no Brasil era média e lá vira classe trabalhadora. E, nos Estados Unidos, é essa classe trabalhadora que tem legitimidade para abrir uma organização não-governamental de imigrantes e não a classe média politizada. Daí o porquê de essa pessoa, que não se considera líder por não ter uma base na comunidade, sabiamente ter buscado o "Centro do Imigrante Brasileiro". O diretor executivo desse "Centro" também comunga do sentido político da organização, mas, ao mesmo tempo, pela sua profunda identidade com os trabalhadores e com a Igreja Evangélica, consegue fazer a transição do político para o social, e esse é o segredo do sucesso do "Centro" por ele dirigido. 
A classe média politizada, que é constituída pelos chamados líderes, no decorrer desses últimos dez anos, vem se articulando não apenas entre si nas suas próprias reuniões e mobilizações políticas, como também na órbita do Consulado Brasileiro de Boston. A atuação do consulado foi diferente segundo os quatro cônsules que estiveram (ou do que está atualmente) à sua frente. O primeiro teve uma atuação pouco destacada e o vice-cônsul era a pessoa mais ativa, que aliás antecipou a proposta do "Consulado itinerante" quando ia às localidades mais distantes, sobretudo Framingham, para atender a demandas da comunidade. Foi daí que nasceu seu vínculo com aquela cidade, que o levou à proposta da criação do "Conselho de Cidades Irmãs" com Santa Luzia. O segundo cônsul institucionalizou a proposta do Itamaraty de criação do "Consulado itinerante" e do "Conselho de cidadãos". Foi com ele que se iniciou um contato mais direto com os líderes de comunidade, o que teve continuidade e foi aprofundado com o terceiro cônsul. Esse tinha duas pessoas no próprio Consulado que eram mais diretamente vinculadas à comunidade dos líderes, participando de suas reuniões e, às vezes, de manifestações políticas. Já o último cônsul é muito criticado pelas lideranças politizadas, por ter adotado uma postura de afastamento em relação à comunidade dos líderes e dado prioridade à eficiência no trabalho de emissão de documentos; ao passo que, pelas lideranças menos politizadas e com um trabalho adstrito à prestação de serviços, ele é bem-aceito. A insatisfação da classe média politizada atual talvez se explique, em parte, pelo fato de essa ter tido nos consulados anteriores uma forma de reconhecimento, que se manifestava aliás socialmente nos eventos festivos promovidos pelo Consulado, para os quais era convidada, o que deixou de acontecer desde 2004, quando o novo cônsul assumiu suas funções.

Voltando à pergunta colocada anteriormente, se os brasileiros estão preparados para enfrentar o desafio de arcar com um "Centro Cultural" que abrigue várias atividades e tenha uma presença física marcada no espaço territorial de Boston, acredito que estão a caminho disso, e só chegarão lá à medida que enfrentarem o próprio desafio. Esse prédio pode justamente dar uma oportunidade de ouro para um aprendizado importante para os líderes comunitários brasileiros, que é a de se organizarem para uma atuação nas áreas de prestação de serviços, fundamental para lhes propiciar recursos financeiros e alargar sua base de apoio. Fazer isso sem perder o lado combativo da luta política que levaram na bagagem do Brasil talvez seja a síntese que dará a marca das organizações brasileiras nos próximos dez anos.

Notas

1 Este artigo tem como base o artigo publicado na Revista São Paulo em Perspectiva, v.19, n.3, 2005.

2 Lembre-se de que o Dia do Trabalho nos Estados Unidos, país que foi palco dos incidentes de perseguição e morte de trabalhadores que deu origem a essa comemoração 
no mundo, não é comemorado no $1^{\circ}$ de maio, mas sim em uma outra data sem nenhum simbolismo relacionado à luta dos trabalhadores por seus direitos.

3 A lei mexicana aprovada em fins de 2005 , que passou a exigir visto para os brasileiros viajarem ao México, foi uma tentativa de frear essa migração ilegal de brasileiros.

4 Dados retirados do site de Framingham.

5 Dados da jornalista Liz Mineo para o jornal Metrowest Daily News em 23.11.2003.

6 Framingham faz parte de uma área geográfica delimitada por fatores mais econômicos do que políticos, na qual a cidade possui posição de liderança, chamada The South Middlesex Region, ou simplesmente Metrowest.

7 Um fato curioso nessa lista amarela é que ela pode servir como uma indicação grosseira da presença de negócios de brasileiros nos Estados Unidos (e mais grosseiramente ainda dos próprios brasileiros). Massachusetts lidera de longe o número de páginas na lista (24), seguido pelos estados da Flórida e New Jersey (16 cada um), depois Connecticut (11), Nova York (8), Califórnia (6) e finalmente Geórgia e Pensilvânia (4 cada um).

8 Esses estabelecimentos compreendem: dois açougues; três escritórios de advogados; uma agência de publicidade; uma agência de viagem; duas lojas de computadores e assistência técnica a computador; quatro revendedoras e oficinas de automóvel; quatro butiques; uma loja de carpete; uma loja de CD e vídeo; quatro escritórios de contadores; três consultórios de dentistas; dois salões de estética; uma loja de filmagem; uma financeira; duas floriculturas; duas lojas de fotógrafos; uma gráfica; uma imobiliária; uma imprensa; quatro joalherias; cinco consultórios de médicos; uma loja de mudanças; quatro padarias e confeitarias; duas lojas de perfumes; duas pizzarias; um posto de gasolina; duas lojas de produtos brasileiros; um consultório de fisioterapia e quiropatia; três lojas de remessas; dois restaurantes; seis salões de beleza; uma loja de videoprodução.

9 Por causa dos escândalos de pedofilia, a Igreja teve que pagar muitas indenizações e, por isso, fechou vários templos, incluindo aquele onde estava sediado o "Centro".

10 Sobre isso, vale lembrar Maxine Margolis (1994), que se referia aos imigrantes brasileiros de Nova York como uma população invisível.

Referências bibliográficas

BOSTON GLOBE. Boston, 11 Dez. 1994.

FOLHA DE S.PAULO. São Paulo, 5 maio 2005. Folha Mundo.

HALTER, M. (Ed.) New migrants in the Marketplace: Boston, Ethnic Entrepreneus. Amherst: University of Massachusetts Press, 1995.

MARGOLIS, M. Little Brazil: imigrantes brasileiros em Nova York. Campinas: Papirus, 1994.

METROWEST DAILY NEWS, 23 Nov. 2003.

O ESTADO DE S. PAULO. S. Paulo, 23 de abril de 2006.

O ESTADO DE S. PAULO. S. Paulo, 28 de abril de 2006.

SALES, T. Brasileiros longe de casa. São Paulo: Cortez, 1999. 
SALES, T.; LOUREIRO, M. Imigrantes brasileiros adolescentes e de segunda geração em Massachusetts, EUA. Revista Brasileira de Estudos de População, v.21, n.2, jul./dez. 2004.

RESUMO - O ARTIGO trata do avanço do nível organizativo dos imigrantes brasileiros na Região Metropolitana de Boston, nos Estados Unidos. Baseado em uma pesquisa realizada em outubro de 2005, faz um histórico das várias organizações criadas pelos imigrantes brasileiros entre 1995 a 2005 nas cidades de Framingham, Boston, Somerville e Cambridge. A conclusão é de que os brasileiros avançaram mais em sua organização política, em conseqüência da bagagem cultural que alguns líderes levaram consigo do Brasil, do que nas áreas de prestação de serviços.

PALAVRAS-CHAVE: Migração internacional, Imigrantes brasileiros nos Estados Unidos, Organizações não-governamentais.

ABSTRACT - THIS ESSAY examines how Brazilian immigrants in the metropolitan region of Boston, USA, are becoming increasingly organized. Based on an October 2005 survey, it lists the various organizations created by Brazilian immigrants from 1995 to 2005 in Framingham, Boston, Somerville, and Cambridge. The conclusion is that Brazilians have advanced more in terms of political organization (because of the cultural baggage some leaders brought from Brazil) than in the service industry.

KEYWORDS: International migration, Brazilian immigrants in the United States, Nongovernmental organizations.

Teresa Sales é socióloga, professora livre-docente e pesquisadora do Núcleo de Estudos de População da Unicamp. @ - tsales@uol.com.br

Recebido em 2.5.2006 e aceito em 5.5.2006. 